\title{
Congenital Mucocele of the Nasal Dorsum: A Case Report
}

\author{
Case Report $\$ Seçil Bahar Dal, ๑ Ömer Faruk Ünal \\ Department of Otorhinolaryngology, Vehbi Koç Foundation American Hospital, İstanbul, Turkey
}

\begin{abstract}
Congenital nasal dorsum cysts are very rare lesions. Its differential diagnosis lies between gliomas, dermoid cysts and encephaloceles. We present a case of solitary congenital external nasal cyst with no intranasal fistulous tract connection in a newborn. Histopathologic analysis of the mass demonstrated findings consistent with an external mucocele. Total excision with external open approach provided the cure with good cosmetic outcome. This is the first report presenting an external mucocele in a newborn in the literature. External mucoceles should be kept in mind in the differential diagnosis of congenital nasal dorsum masses.

Keywords: Nasal dorsum, mucocele, congenital, cyst, newborn, pediatric otorhinolaryngology
\end{abstract}

ORCID ID of the authors:

S.B.D. 0000-0003-3005-3595; Ö.F.U. 0000-0001-5692-2475.

Cite this article as: Bahar DalS, Ünal ÖF. Congenital Mucocele of the Nasal Dorsum: A Case Report. Turk Arch Otorhinolaryngol 2021

Corresponding Author: Seçil Bahar Dal; drsecilbahar@gmail.com

Received Date: 21.12 .2020 Accepted Date: 01.02 .2021

Content of this journal is licensed under a Creative Commons Attribution 4.0 International License. Available online at www.turkarchotolaryngol.net (c) (i) \$

\section{Introduction}

Congenital nasal dorsal masses are rare, but mostly well-known pathologies. Differential diagnosis of these nasal lesions includes nasal dermoid cysts, gliomas and encephaloceles (1).

In this article we report the case of a newborn with a congenital external mucocele located on the tip of the nose. To the best of our knowledge, such a malformation in a newborn has not been described in the literature to date.

\section{Case Report}

A one-month-old male baby was observed to have a lesion on his nose at birth. The $2 \times 2 \mathrm{~cm}$, cystic and round shaped mass was located on the tip of the nose (Figure 1).

Magnetic resonance imaging (MRI) showed a well-circumscribed, T2 hyperintense, homogeneous cystic mass on the tip of the nose with no evidence of any fistulous tract into the cranial or nasal cavity (Figure 2).

Direct open approach with an alar rim incision was used to remove the cyst. The 
cyst was just under the skin without any connection to the cartilages of the nasal dorsum (Figure 3). We did not observe any connection between the cyst and the nasal cavity during the operation.

Histopathologic examination revealed an external mucocele composed mainly of ciliated epithelium and regions of focal pseudostratified columnar epithelium without lymphoid tissue, seromucous gland, goblet cell, or crypt. Pressure atrophy caused by fluid accumulation was observed in the epithelial lining of the cyst (Figure 4 A,B).

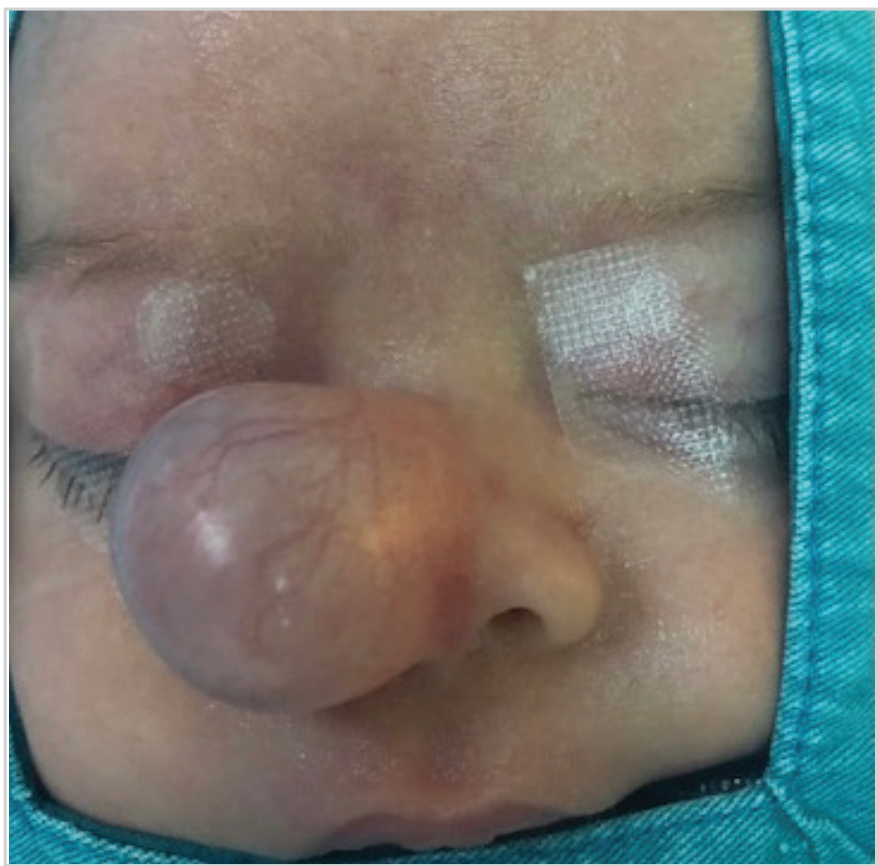

Figure 1. Preoperative view of the patient

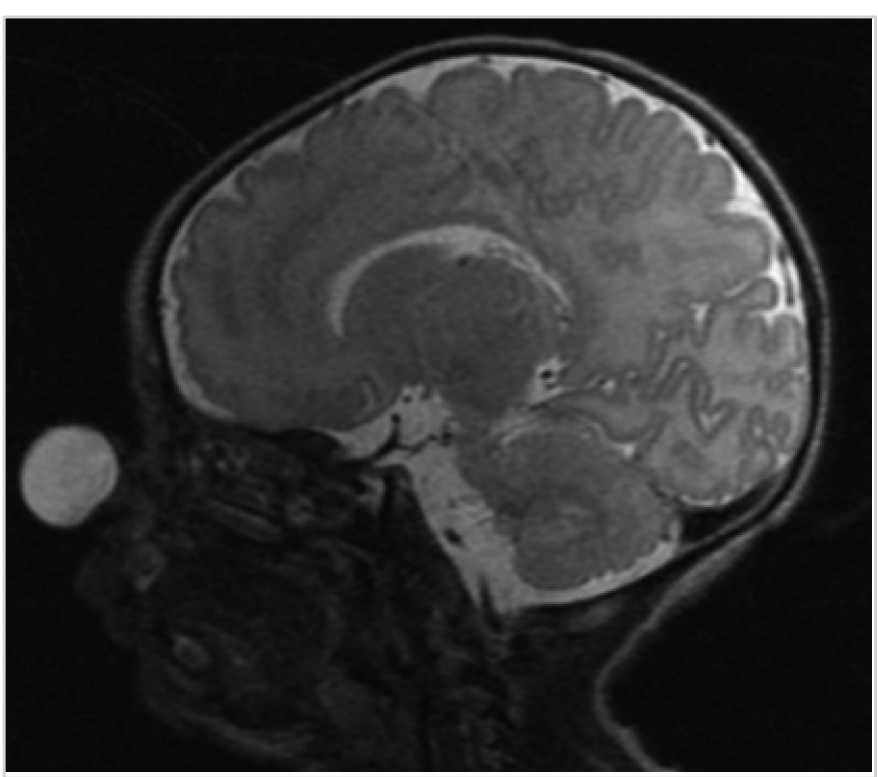

Figure 2. Sagittal T2 MRI view of the lesion MRI: Magnetic resonance imaging
The tip of the nose was packed for two days after the operation. There was no complication during or after the operation. The patient's appearance one month after the

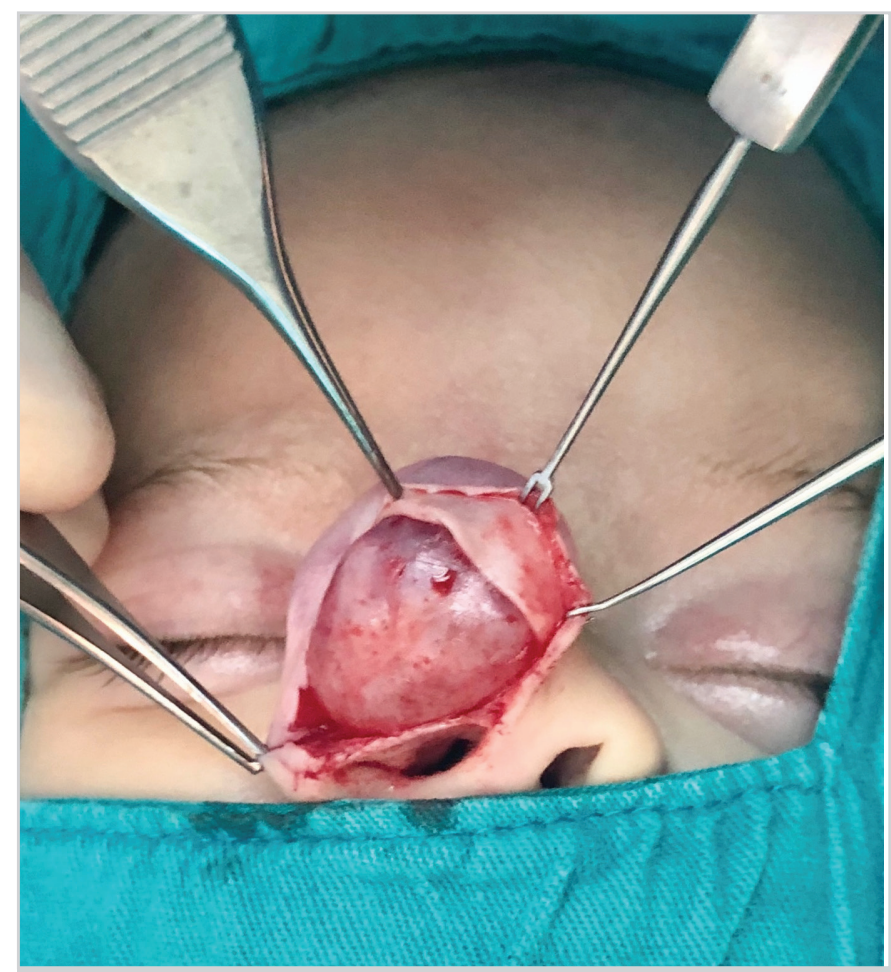

Figure 3. Intraoperative view of the nasal dorsal mass, showing the mucous cyst being dissected from the overlying skin

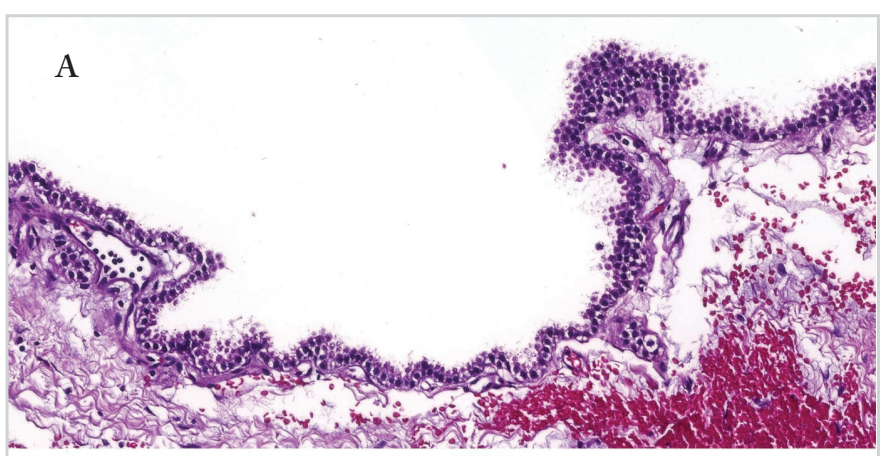

B

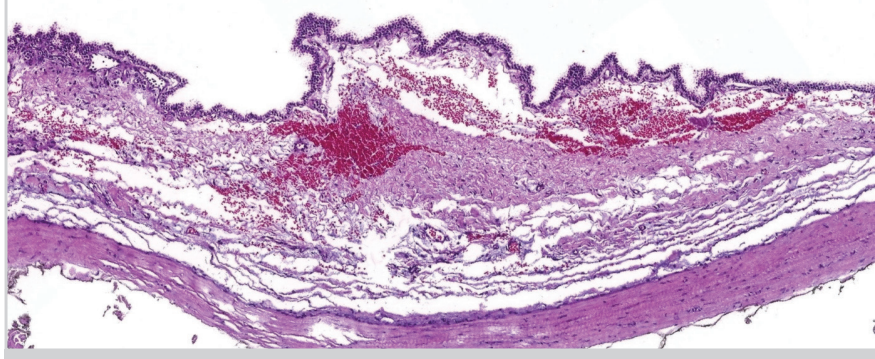

Figure 4 A, B. Histopathologic examination revealed an external mucocele, lined mainly with ciliated epithelium and the regions of focal pseudostratified columnar epithelium (Figure A x72 magnification with 3DHISTECH Case Viewer and Figure B x20 magnification with 3DHISTECH Case Viewer) 
operation is shown in Figure 5. We did not observe any recurrence in a six-month follow-up period.

Informed consent was taken from the father of the patient for publication.

\section{Discussion}

Mucus retention cysts, benign skin adnexal tumors, cholesterol granulomas, dermoid and epidermoid cysts and encephalocele are included in the differential diagnosis of a nasal mucocele (2-4).

After detailed histopathological examination, presented case was diagnosed as an external mucocele. Histopathologically, the most similar lesions to our case are the cyst formations following rhinoplasty. The sites of these cysts vary from the glabellar region to the tip of the nose and the paranasal sinuses. Herniation of the mucosa, interposition or inoculation of the nasal mucosa are supposed to be the most accepted explanations of this entity $(3,5)$.

Similarly, in our case, proliferation of the cells in an ectopic mucous membrane island seems to be an acceptable theory of etiology. Occlusion of sebaceous glands, as reported by Rettinger and Steininger (6), can also lead to such mucous cysts.

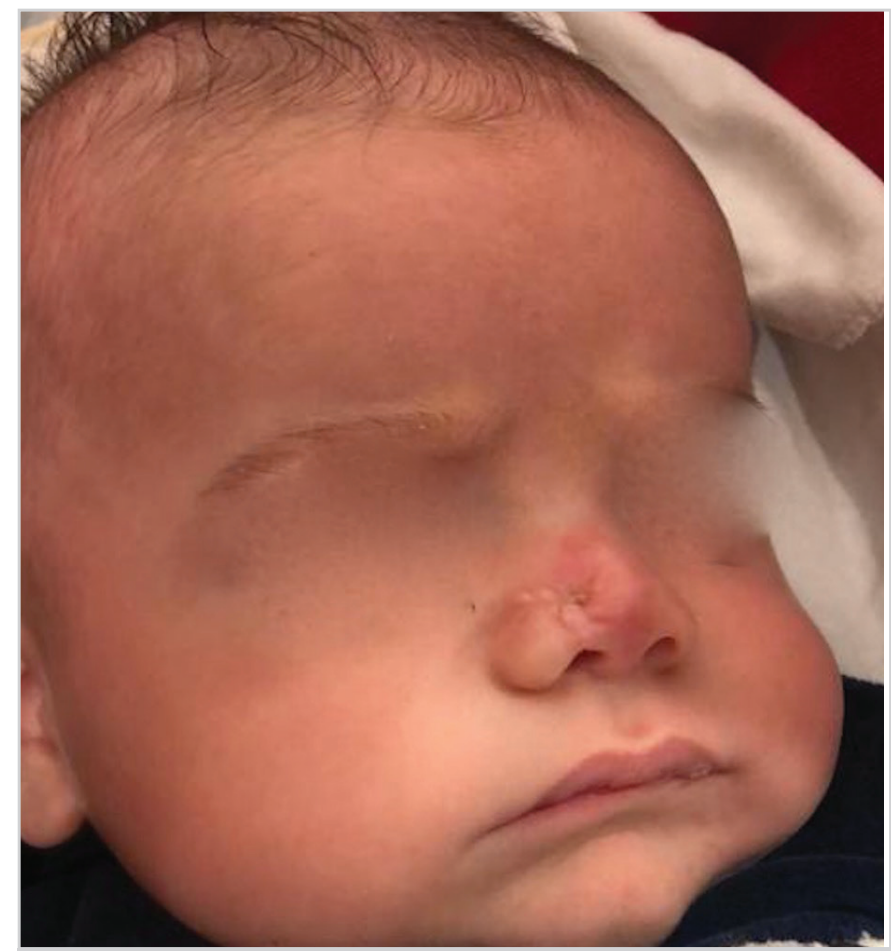

Figure 5. Postoperative first month view of the patient
Comprehensive physical examination is important for diagnosis. Also, preoperative imaging of nasal congenital lesions is an essential tool to confirm the diagnosis. It is important to bear in mind intracranial extension of intranasal masses. Understanding the extent of the lesion with MRI will help to tailor the surgical approach, hence completely excise the lesion and prevent recurrences. In this type of lesions, it is also important to remove the cyst and the fistulous pathway in the same session to avoid possible infectious complications $(1,7)$.

Given the risks of exposure to radiation, computed tomography scanning is not always necessary for diagnosis in young children, as in our case, when MRI findings provide adequate preoperative information. In patients with uncertain MRI findings or when further bone anatomy evaluation is needed, computed tomography scan can also be performed (7). MRI findings were consistent with intraoperative findings and we did not observe any fistulous tract extensions of the cystic mass in the presented case.

The treatment of choice is complete excision with intact capsule. For similar nasal masses, open or closed rhinoplasty approach, endoscopic excision or direct excision with external skin incision can be preferred $(3,7)$. Considering the location of the cyst we preferred a direct external open approach, which provided a wide exposure allowing a safe surgical excision and a relatively good aesthetic result.

\section{Acknowledgements}

The authors gratefully acknowledge Prof. Önder Peker, $\mathrm{PhD}$ (Department of Pathology, American Hospital, İstanbul) for his detailed histopathologic examination.

Informed Consent: Informed consent was taken from the parents of the patient for publication.

Peer-review: Externally peer-reviewed.

Conflict of Interest: The authors declare no conflicts of interest.

Financial Disclosure: There was no financial support.

Authorship Contributions: Conception: S.B.D., Ö.F.Ü., Design: S.B.D., Ö.F.Ü., Supervision: S.B.D., Ö.F.Ü., Funding: S.B.D., Materials: S.B.D., Data Collection and/or Processing: S.B.D., Analysis and/or Interpretation: S.B.D., Literature Review: S.B.D., Writing: S.B.D., Critical Review: S.B.D., Ö.F.Ü. 


\section{Main Points}

- Nasal dorsum cyst in a newborn is a rare lesion.

- Nasal dermoid and epidermoid cysts, gliomas, encephaloceles, benign skin adnexal tumor and cholesterol granulomas are wellknown lesions in differential diagnosis.

- In patients with congenital nasal masses preoperative radiologic examination is crucial for differential diagnosis and for determining the extension of the lesion and the appropriate surgical planning.

- External mucoceles of the nasal dorsum are cyst formations that have been reported following rhinoplasty. However, external mucocele formations in the nasal dorsum can also occur as congenital lesions.

\section{References}

1. Vora N, Kalagiri R, Guillory B, Shetty A, Raju VN, Powitzky RK, et al. Congenital midline nasal anomalies. Proc (Bayl Univ Med Cent) 2017; 30: 459-60. [Crossref]
2. Dionyssopoulos A, Nikolis A, Papaconstantinou A, Kakas P, Miliaras D, Kekes G. Mucous cysts of the nose: a postrhinoplasty complication? A long-term follow-up. Ann Plast Surg 2010; 64: 381-4. [Crossref]

3. Romo T 3rd, Rizk SS, Suh GD. Mucous cyst formation after rhinoplasty. Arch Facial Plast Surg 1999; 1: 208-11. [Crossref]

4. Topdag M, Iseri M, Sari F, Erdogan S, Keskin IG. Paranasal sinus mucoceles: our clinical experiments. Int J Clin Exp Med 2015; 8: 18518-22. [Crossref]

5. Pausch NC, Bertolini J, Hemprich A, Hierl T. Inclusion mucous cysts of the nose: a late complication septorhinoplasty in two cleft lip patients. Cleft Palate Craniofac J 2010; 47: 668-72. [Crossref]

6. Rettinger G, Steininger H. Lipogranulomas as complications of septorhinoplasty. Arch Otolaryngol Head Neck Surg 1997; 123 : 809-14. [Crossref]

7. Herrington H, Adil E, Moritz E, Robson C, Perez-Atayde A, Proctor M, et al. Update on current evaluation and management of pediatric nasal dermoid. Laryngoscope 2016; 126: 2151-60. [Crossref] 